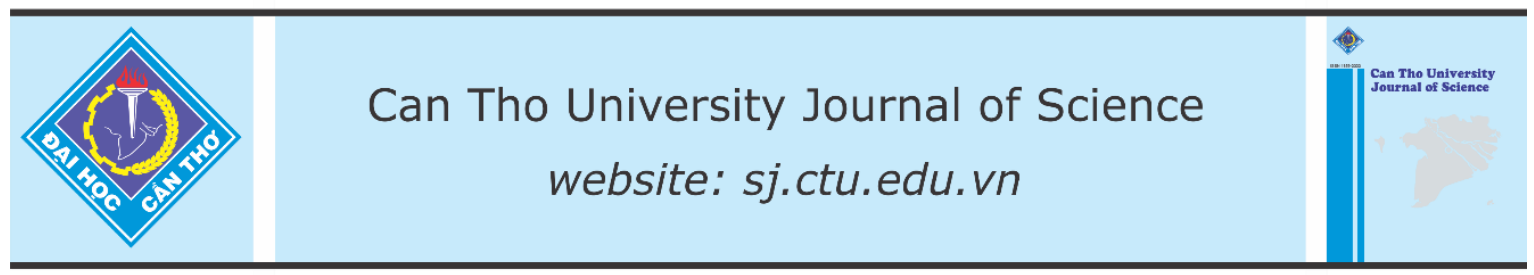

DOI: 10.22144/ctu.jen.2021.022

\title{
Screening utilization of different natural prebiotic extracts by probiotic Lactobacillus sp. for development of synbiotic for aquaculture uses
}

\author{
Huynh Truong Giang*, Vu Hung Hai, Phan Thi Cam Tu, Pham Thi Tuyet Ngan and Vu Ngoc Ut \\ College of Aquaculture and Fisheries, Can Tho University, Viet Nam \\ *Correspondence: Huynh Truong Giang (email: htgiang@ctu.edu.vn)
}

\section{Article info.}

Received 22 Feb 2021

Revised 15 Apr 2021

Accepted 04 Jun 2021

\section{Keywords}

Lactobacillus, Litopenaeus vannamei, natural prebiotic extract, probiotic, synbiotic

\begin{abstract}
The study is aimed to develop a relevant synbiotic to promote growth performance of the whiteleg shrimp, Litopenaeus vannamei. For this, four common natural fiber extracts from Arcera banana, Siamese banana, yellow sweet potato, and white sweet potato were screened for supporting the growth of Lactobacillus sp. which was isolated from whiteleg shrimp intestines with probiotic activity, prebiotic score, and ability to induce bacterial enzyme activities of protease, leu-aminopeptidase, and $\alpha$-amylase. Results showed that Lactobacillus sp. was able to utilize all extracts from banana and sweet potato as the sole carbon sources. At 24 hours of culture, the growth of Lactobacillus sp. was highest after adding the extract from white sweet potato as the sole carbon source. Considering pathogenic bacteria, including Vibrio parahaemolyticus, white sweet potato extract had the highest prebiotic score with a mean of 0.25 as compared with those of $V$. harveyi with a mean of 0.16 . White sweet potato extract induced the highest activities of protease. These results indicated that white sweet potato extract was more suitable for combining with Lactobacillus sp. as a synbiotic for shrimp culture.
\end{abstract}

\section{INTRODUCTION}

Since 2004, whiteleg shrimp, Litopenaeus vannamei has been considered the most popular cultured penaeid species in Asian countries (Liao \& Chien, 2011). In Vietnam, shrimp have changed the export turnover of the fishery sector in general and the shrimp export industry in particular. Due to enthusiastic investment and effort, the whiteleg shrimp farming models are becoming superlative and most professional as compared to other species. Advanced and high techniques have been applied to shrimp farming that results in increase of production of whiteleg shrimp, even being able to cope with adverse changes of the farming environment in recent years. It can be agreed that investment for intensification of whiteleg shrimp culture has been of a step toward of aquaculture industry in Vietnam.
A synbiotic is a nutritional supplement which is a combination of probiotics and prebiotics (Cerezuela et al., 2011; Huynh et al., 2017). The synergistic effect of a probiotic is chosen based on its effects on the host, and the prebiotic must specifically stimulate the growth and enzyme activities of the probiotic (Kolida \& Gibson, 2011). Among probiotic bacteria, Lactobacillus species are potential bacterial strains that can be combined with prebiotic(s) to form the suitable synbiotic products for aquaculture uses, especially for whiteleg shrimp culture (Huynh et al., 2017, 2018a, 2018b). Lactobacilli are important microbes that are known for their fermentative ability as well as their health and nutritional advantages and these species also exert antimicrobial activity against pathogens (Rossland et al., 2003). Among prebiotics, isomaltooligosaccharide (IMO) 
and galactooligosaccharide (GOS) have been used to combine with Bacillus megeterium or Lactobacillus plantarum for enhancement of the whiteleg shrimp (Li et al., 2009; Huynh et al., 2018b). In addition, mannan oligosaccharide (MOS), fructooligosaccharide (FOS), or inulin, were also used as prebiotics for synbiotics development. However, Huynh et al. (2017) stated that using these purified commercial prebiotics for developing the synbiotics mayincrease the feed costs in intensive aquaculture. Therefore, in this study, Lactobacillus isolated from whiteleg shrimp's intestine was chosen to screen with several natural prebiotics extracted from natural fruits and vegetables, including Arcera banana, Siamese banana, yellow sweet potato, and white sweet potato which were considered as the sources of natural oligosaccharide (Rosas-Ramírez et al., 2008). The results could provide the evidence for prebiotic extracts utilization by probiotic Lactobacillus sp. for further studies in improving growth performance of the whiteleg shrimp culture in the Mekong Delta, Vietnam.

\section{MATERIALS AND METHODS}

\subsection{Chemicals and culture media}

De Man, Rogosa and Sharpe (MRS) broth (DifcoTM Laboratories, Sparks, MD, USA), tryptone (a pancreatic digest of casein), sodium chloride, dipotassium hydrogen phosphate, Tris- $\mathrm{HCl}, p$ nitroaniline ( $p$-NA) amino acid, o-nitrophenyl-Dgalactopyranoside (ONPG), bovine serum albumin (BSA), proteose peptone No.3, beef extract, yeast extract, ammonium citrate, magnesium sulfate, manganese sulfate were used. All chemicals used were analytical grade.

\subsection{Probiotic bacteria}

Probiotic Lactobacillus sp. TV32 strain was isolated from whiteleg shrimp intestine following the standards of Food and Agriculture Organization/ World Health Organization (FAO/WHO, 2006) in our previous study (Huynh et al., 2020). The strain was stored at the Laboratory of Beneficial Bacteria for Aquaculture, Department of Applied Hydrobiology, College of Aquaculture and Fisheries, Can Tho University. The Lactobacillus sp. was cultured in MRS broth medium combined with skim milk and glycerin at the suitable rate for long-term storage as previously described by Huynh et al. (2018b) and stored at $-80^{\circ} \mathrm{C}$ for further experiments.

\subsection{Preparation of prebiotic extracts}

This study was carried out from January to December 2019 at the Laboratory of Beneficial Bacteria for
Aquaculture, Department of Applied Hydrobiology, College of Aquaculture and Fisheries, Can Tho University. Crude natural prebiotics were extracted from several common fruits and roof vegetables, including Arcera banana variety, Siamese banana variety (Musa acuminata), orange-fleshed sweet potato variety (Ipomoea batatas), and white sweet potato variety (I. batatas).

For bananas, the extraction procedure was based on the method previously described by Boonmee \& Rengpipate (2015). Banana was peeled and sliced thinly. Ten grams of sliced bananas were grounded in $100 \mathrm{~mL}$ of $100^{\circ} \mathrm{C}$ water and then stood for 10 mins. The supernatant was filtered and centrifuged at $10,000 \mathrm{rpm}$ at $4^{\circ} \mathrm{C}$ for $10 \mathrm{mins}$ and then collected the clear solution and freeze-drying until powder form. The powder used as banana extract (BE) was used for the experiment. In order to gain a large volume, the volume of BE was sufficiently extracted for the experiment then refrigerated at $4{ }^{\circ} \mathrm{C}$ for later uses.

For sweet potatoes, two sweet potato varieties were used. Sweet potatoes $(500 \mathrm{~g})$ were steamed at $100^{\circ} \mathrm{C}$ for 30 mins. The mixture was dried at $55^{\circ} \mathrm{C}$ for 18 hours. Next, the mixture was crushed and sifted through the mesh until the mixture was powdered. Then, $10 \mathrm{~g}$ of potato starch were dissolved in 100 $\mathrm{mL}$ of $70 \%$ ethanol, stirred for 15 hours at room temperature. The mixture was filtered through glass filter paper and centrifuged at $10,000 \mathrm{rpm}$ for 10 mins to remove impurities. Then the collected filtrates were subjected to rotary evaporator to remove the ethanol then dried in a vacuum freeze dryer for further use (Marlida et al., 2014). Thus, after extraction, there were four mixtures for evaluation of prebiotic activity in total. The extracts were stored at $-4^{\circ} \mathrm{C}$ for further uses.

\subsection{Prebiotic utilization of probiotic Lactobacillus sp.}

The purpose of the experiment was to evaluate the prebiotic utilization, in which prebiotic extracts was used as the sole of carbon sources for lactic fermentation. The method for evaluation was based on Huynh et al. (2018b). Briefly, the probiotic Lactobacillus sp. firstly cultured in MRS medium at $37^{\circ} \mathrm{C}$ for 24 hours, and then the bacteria were centrifuged at $3000 \mathrm{rpm}$ for $10 \mathrm{mins}$ at $4^{\circ} \mathrm{C}$. The bacteria were washed twice and re-suspended in a modified-MRS medium ( $m$-MRS). Subsequently, the bacterial solution was inoculated on m-MRS agar plates containing $2 \%$ of the natural prebiotic extract with Bromocresol purple (BP) indicator. The ability of Lactobacillus sp. to utilize extract as a source of carbon was 
observed through the discoloration of the surrounding environment from violet to yellow. In addition to the extracts from natural products, Lactobacillus sp. that cultured on the m-MRS without extracts/glucose and with glucose were served as negative and positive controls, respectively.

\subsection{Evaluation of the growth stimulation of Lactobacillus sp. by prebiotic extracts}

Lactobacillus sp. TV32 bacteria were prepared as described in Section 2.4. Added $5 \mathrm{~mL}$ of Lactobacillus sp. to $95 \mathrm{~mL}$ of $m$-MRS medium, and then the bacterial solution was then transferred to $15 \mathrm{~mL}$ test tubes. Growth of Lactobacillus sp. was assessed as increases in absorption at a wavelength of $600 \mathrm{~nm}$ at times $0,2,4,6$ and 24 hours using a spectrophotometer (Alpha Helios, Thermo Fisher Scientific, USA). The $\mathrm{pH}$ was also monitored through the process as one of the indirect indicators of the growth and digestion of carbohydrate mixtures of the extract. Each culture was run in triplicate (Huynh et al., 2018b).

\subsection{Evaluation of the ability of prebiotic extracts to induce growth of Vibriosis}

Prebiotic extracts were evaluated for the ability of the pathogenic bacteria to stimulate growth. Some common pathogenic strains that are known as the disease causative agents to whiteleg shrimp, including Vibrio parahaemolyticus and $V$. harveyi were selected for evaluation. The method was as following a study of Huynh et al. (2018b). Briefly, bacterium $V$. harveyi or $V$. parahaemolyticus was prepared by growing on the medium containing tryptone, soytone, $\mathrm{NaCl}$ with $2 \%$ glucose or $2 \%$ of the natural prebiotic extract. The cultures were then incubated at $28^{\circ} \mathrm{C}$ with constant agitation and $\mathrm{OD}_{600}$ values were recorded at a time interval of $0,2,6$, and 24 hours. Each culture was run in triplicate.

\subsection{Evaluation of prebiotic activity score}

The prebiotic score reflects the ability of an oligosaccharide mixture to give probiotics better growth than other bacteria groups (not target bacteria) in the intestinal tract of shrimp and compared with using glucose as a form of sugar needed for the development of lactic bacteria. Positive prebiotic carbohydrates if they are digested well as glucose by beneficial bacteria, and complementary synbiotic are selective by probiotic in digestion while the group of pathogenic bacteria limits digestion. Negative prebiotic score when Lactobacillus sp. developed in environments with prebiotic supplements lower than glucose supplementation medium and/or poorer growth of pathogenic bacteria. The prebiotic score was evaluated according to the method of Mazzola et al. (2015) with slight modifications by Huynh et al. (2018b). Lactobacillus sp. cultured in m-MRS medium supplemented with $2 \%$ glucose or $2 \%$ prebiotic extract as a carbon source. Optical density (OD) values were recorded at 0 and $24 \mathrm{~h}$. The prebiotic score was calculated as previous study of Huynh et al. (2018b)

\subsection{Enzyme activity of Lactobacillus sp. induced by prebiotic extracts}

The ability of Lactobacillus sp. in secretion and increases of enzyme activity are important implications for prebiotic utilization and proteolysis that are essential for probiotic biomass growth. Therefore, the purpose of this test was to screen the prebiotic extract(s) that can induce the highest activity in terms of protease derived from Lactobacillus sp. The probiotic was cultured in $m$-MRS medium with $2 \%$ of each natural prebiotic extracts and medium containing $2 \%$ glucose was served as a control. After 24 hours of incubation at $37^{\circ} \mathrm{C}$, the cells were removed by centrifugation at $3000 \mathrm{rpm}$ for $10 \mathrm{mins}$ at $4^{\circ} \mathrm{C}$ and the cell-free supernatants (CFS) obtained. The protease activity of CFS of Lactobacillus sp. were evaluated according to the method described by Huynh et al. (2018b). For this, the protease activity was assayed at $40^{\circ} \mathrm{C}$ in $100 \mathrm{mmol} / \mathrm{L}$ Tris- $\mathrm{HCl}$ buffer ( $\mathrm{pH} 9.0)$. The culture $(100 \mu \mathrm{L})$ was incubated with $100 \mu \mathrm{L}$ of a $1 \%$ casein solution (prepared in Tris-HCl buffer, $\mathrm{pH}$ 7.0) for 10 mins at $37^{\circ} \mathrm{C}$. The reaction was stopped by adding $500 \mu \mathrm{L}$ of 5\% (v/v) Trichloroacetic acid. After $20 \mathrm{mins}$, the contents were centrifuged at $3000 \times g$ and $4^{\circ} \mathrm{C}$ for 20 mins, and the supernatant was measured by a modified Lowry's method. One unit of protease was equivalent to the amount of enzyme required to release $1 \mu \mathrm{g}$ of tyrosine $/ \mathrm{mL} / \mathrm{min}$ under standard assay conditions.

\section{RESULTS}

\subsection{Prebiotic utilization of probiotic Lactobacillus sp.}

After 24 and 48 hours, the growth of Lactobacillus sp. was observed clearly by the colonies in disk containing glucose and natural prebiotic extracts from Arcera banana, Siamese banana, orange-fleshed sweet potato, and white sweet potato as compared to the negative control (-) (Figures 1\&2). It is, therefore, concluded that the prebiotic extracts could be used as the sole of carbon sources for lactic fermentation by Lactobacillus $\mathrm{sp}$. 


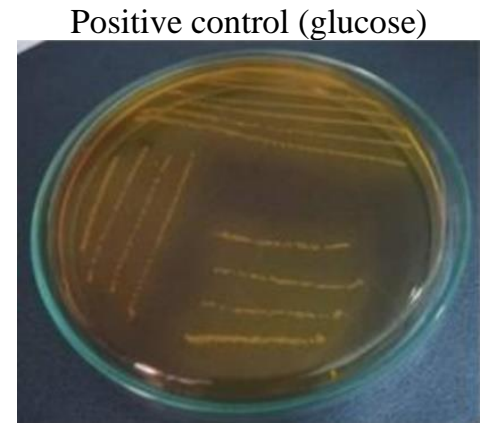

Siamese banana extract

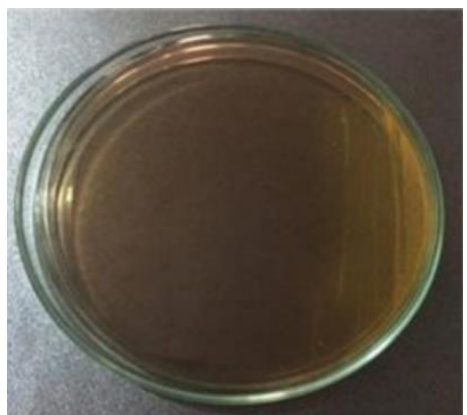

Negative control (no sugar)

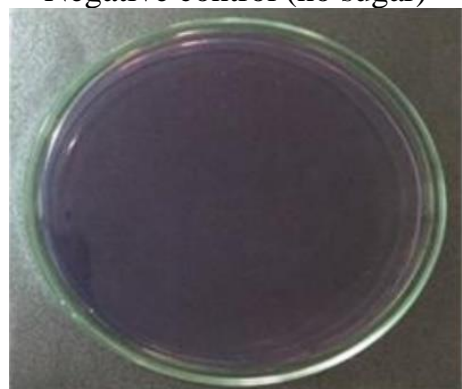

Orange-fleshed sweet potato extract

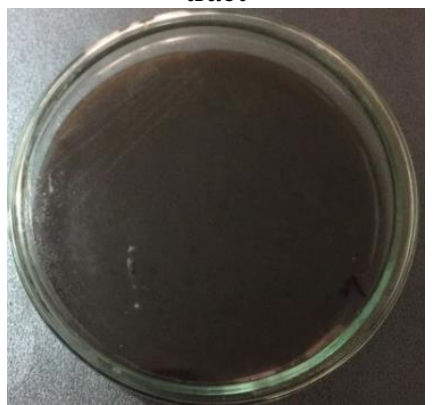

Arcera banana extract

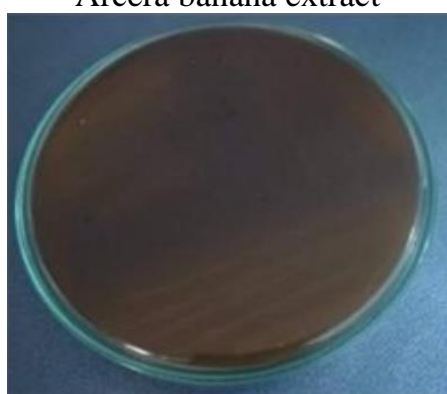

White sweet potato extract

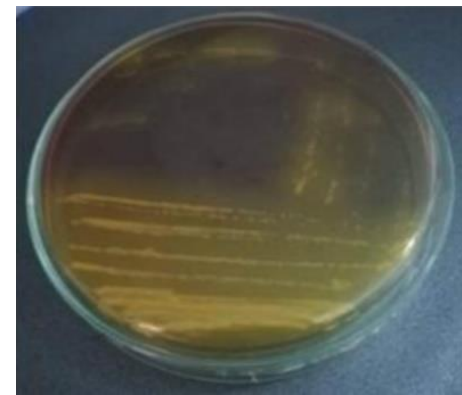

Figure 1. Natural prebiotic extracts utilization ability of the probiotic Lactobacillus sp. after 24 hours

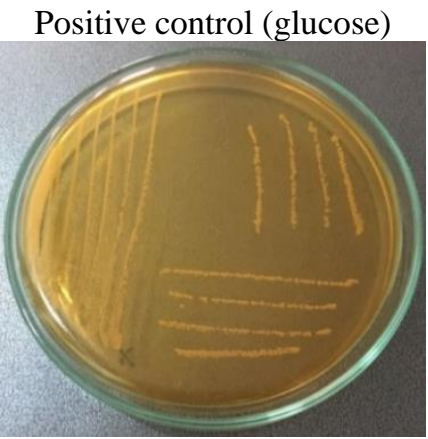

Siamese banana extract

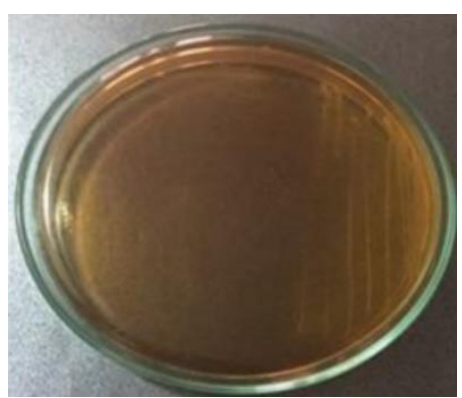

Negative control (no sugar)

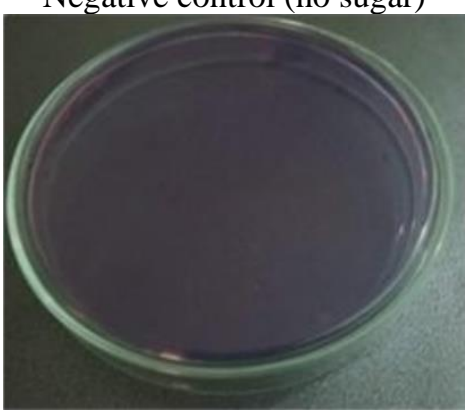

Orange-fleshed sweet potato extract

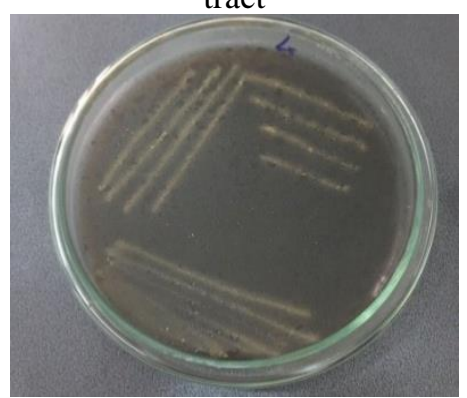

Arcera banana extract

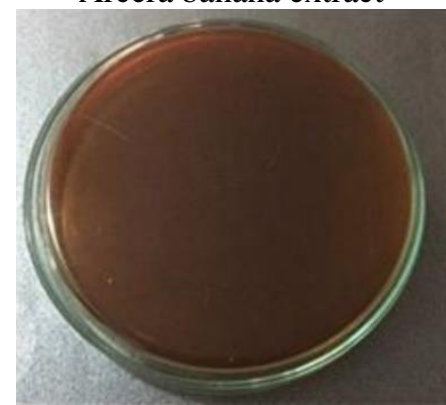

White sweet potato extract

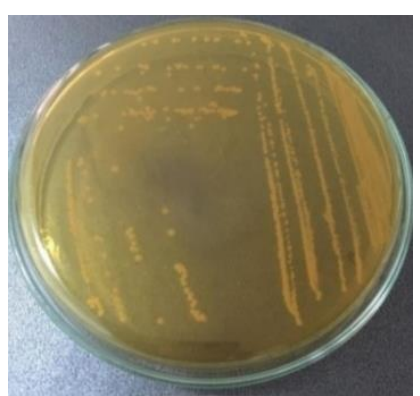

Figure 2. Natural prebiotic extracts utilization ability of the probiotic Lactobacillus sp. after 48 hours 


\subsection{Evaluation of the growth stimulation of Lactobacillus sp. by prebiotic extracts}

Growth stimulation of Lactobacillus sp. by natural prebiotic extracts is shown in Figure 3. Growth levels of Lactobacillus sp. among natural prebiotic extracts and glucose did not significantly differ after 6 hours of culture. However, growth of Lactobacillus sp. significantly increased in the treatment adding

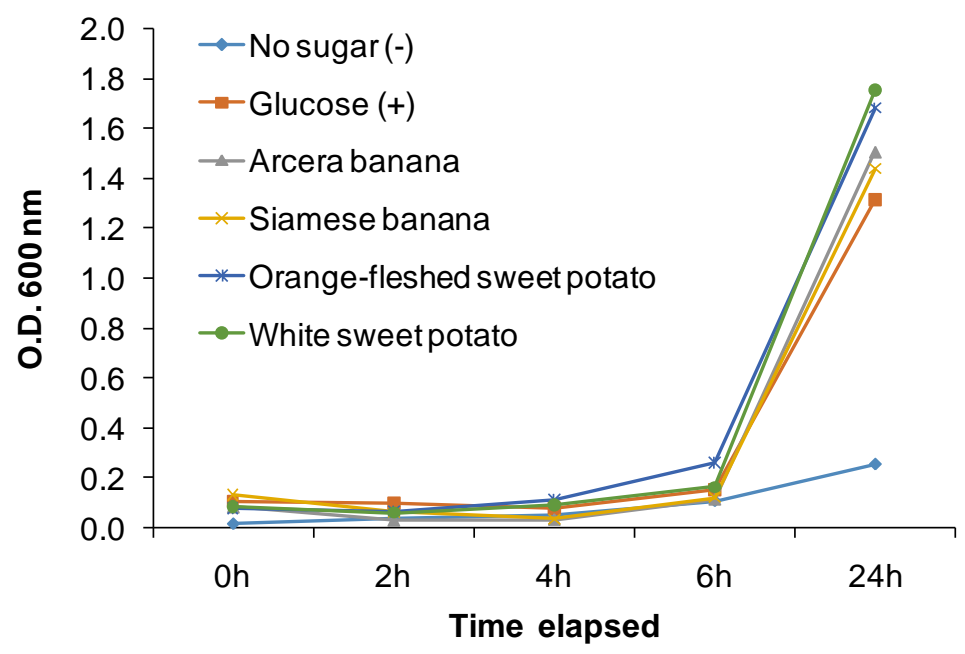

Figure 3. Growth stimulation of Lactobacillus sp. by natural prebiotic extracts

No sugar or glucose respectively served as the negative and positive controls

\subsection{Evaluation of the ability of prebiotic extracts to induce growth of Vibriosis and prebiotic scores}

Figures 4 show the white sweet potato extract stimulated the growth of pathogenic bacteria $V$. parahaemolyticus. Obviously, the optical densities of $V$. parahaemolyticus bacterial suspensions at 2 and 24 hours were 0.338 and 1.259 , respectively. However, results also were assumed that the growth of $V$.

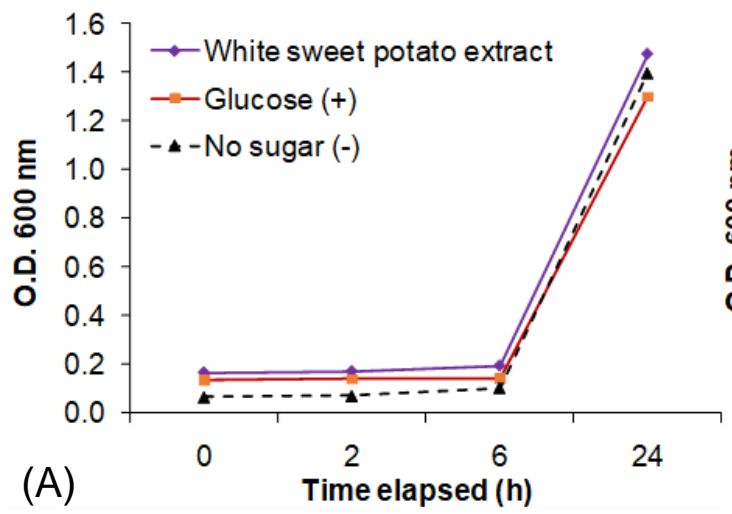

with natural prebiotic extracts as the sole carbon sources as compared with those of negative control (no sugar added). Results also indicated that the growth of Lactobacillus sp. was highest in the medium containing white sweet potato extract as the sole carbon source over 24 hours. Therefore, white sweet potato extract was selected for further tests.

harveyi did not affected by sugar as the sole of carbon source. The pathogenic bacteria were used as references and averaged scores obtained for the Lactobacillus sp. Considering V. haveryi and V. parahaemolyticus, the mean prebiotic scores were 0.16 and 0.25 , respectively (Figure 5 ). The prebiotic scores indicated that among the $V$. haveryi and $V$. parahaemolyticus community, white sweet potato extract could more stimulate growth of $V$. haveryi than $V$. parahaemolyticus.

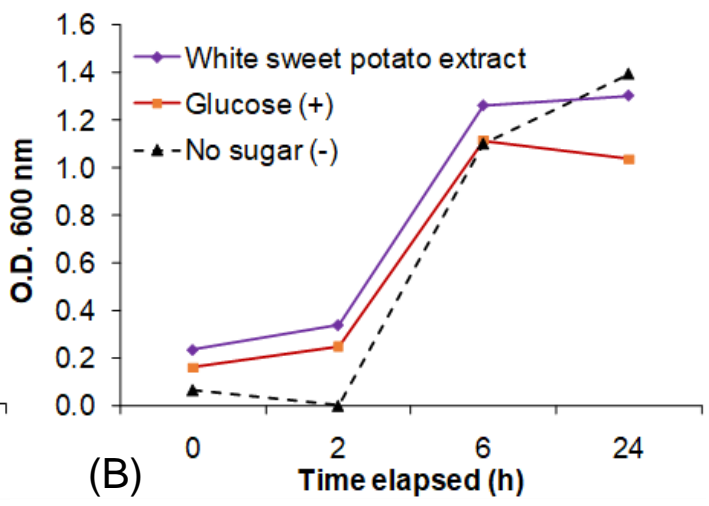

Figure 4. Growth stimulation of V. parahaemolyticus (A) and $V$. harveyi (B) by white sweet potato extract

No sugar or glucose respectively served as the negative and positive controls 


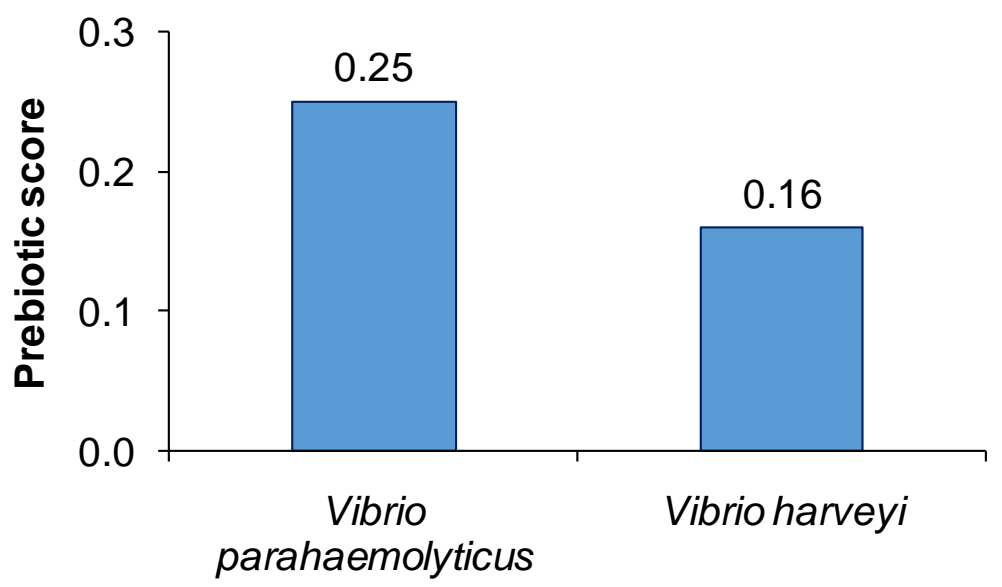

Figure 5. Prebiotic scores of white sweet potato extract obtained from Lactobacillus sp. considering and $V$. haveryi and $V$. parahaemolyticus

3.4. Extracellular protease activity of Lactobacillus sp. induced by prebiotic extracts

Lactobacillus sp. cultured with white sweet potato extract as the sole carbon source produced significantly higher protease activity than when cultured with glucose (positive control). Protease enzyme activity was a mean of $208 \pm 6.8$ units $/ \mathrm{mL} / \mathrm{min}$ (Figure 6).

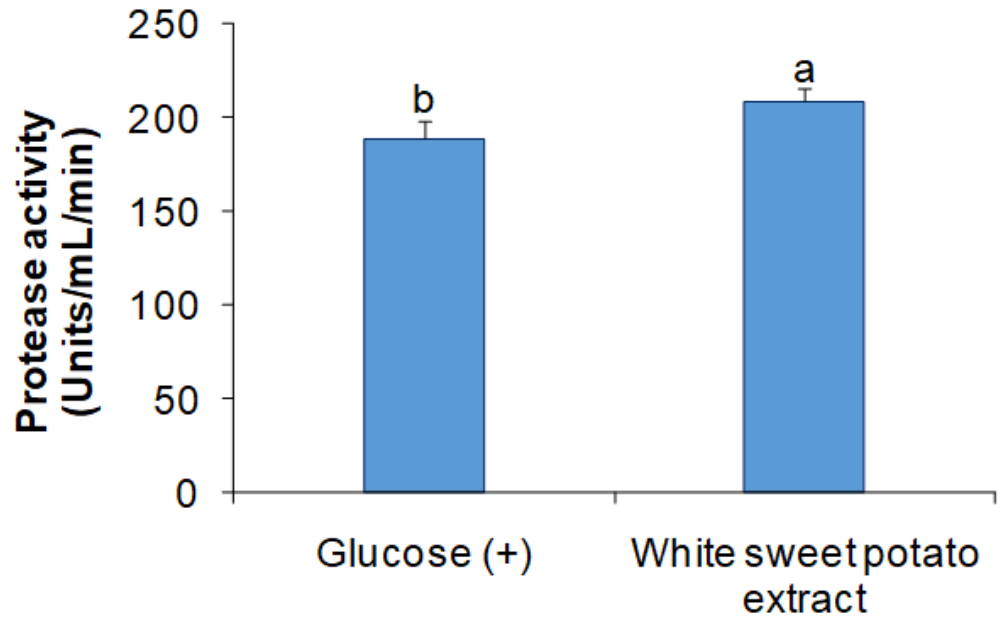

Figure 6. Activities of protease enzymes produced by Lactobacillus cultured in the modified MRS medium containing white sweet potato extract as the sole carbon source

Each bar represents the mean value from triplicate determinations with the standard error. Data with different letters significantly differ ( $p<0.05)$ among treatments.

\section{DISCUSSION}

The extracts from banana (Musa) and sweet potato (Ipomoea) have been used in combination with probiotic in fish and shrimp. In fact, Widanarni and Tanbiyaskur (2015) stated that extract of sweet potato I. batatas var. sukuh in conjunction with probiotic Bacillus sp. NP5 promoted survival rate, growth performance of Nile tilapia Oreochromis niloticus (15-20 g) after 14 days of feeding. In addition, fish were fed the diet containing the extract and Bacillus sp. NP5 significantly improved survival after being challenged with Streptococcus agalactiae at the dose of $10^{4} \mathrm{CFU} /$ fish. Similarly, Marlida et al. (2014) reported that humpback grouper Cromileptes altivelis $(4.75 \pm 0.02 \mathrm{~g})$ fed combination of the 
extract from sweet potato I. batatas and probiotics including Sphingomona paucimobilis, Pseudomonas flourescens had significantly higher survival, growth performance and feed efficiency than those of the control. The authors also revealed that hematological parameters (as hemoglobin, hematocrit, phagocytic activity) and digestive enzyme ( $\alpha$-amylase) significantly enhanced. Most recently, Putra and Romdhohah (2019) investigated the effects of probiotic (Bacillus NP5) and prebiotic (extracted from I. batatas var. sukuh,) on growth and digestive enzyme activity of dumbo catfish (Clarias sp.). The results revealed that a synbiotic (I. batatas var. sukuh + Bacillus NP5) had the growth enhancing effect and feed utilization compared to other treatment (I. batatas var. sukuh or Bacillus NP5 only) on fish. In the whiteleg shrimp L. vannamei, extract from sweet potato Ipomoea have been also used as a prebiotic for health benefits. Obviously, shrimp fed the sweet potato Ipomoea and probiotic SKT-b ${ }^{\circledR} V i b$ rio alginolyticus for 30 days significantly increased growth performance and immune response to co-infection with Infectious Myonecrosis Virus (IMNV) and $V$. harveyi at the dose of $10^{3} \mathrm{CFU} /$ shrimp (Nurhayati et al., 2015). Most interestingly, a study of Boonmee and Rengpipat (2015) stated that extract from banana Musa (ABB group) and B. subtilis S11 in combination form did not show effect on growth performance of shrimp after 90 days of feeding. However, the survival rate of shrimp significantly improved when the shrimp were challenged with $V$. harveyi at dose of $10^{7} \mathrm{CFU} / \mathrm{mL}$ by immersion for 15 days. Previous studies as mentioned above proved the fact that extracts with prebiotic activity from natural fruits and vegetables have been used for improving in implantation of probiotic bacteria along intestinal tract of aquatic animals, thereby exerting the synergistic effects to the host.

Among available prebiotic products, it is not clear which prebiotic carbohydrate is the most suitable substrate for growth of Lactobacillus sp. Among Lactobacillus species, prebiotics may utilize diverse mechanisms dependent on sugar linkages and the bacterial strain (Huynh et al., 2017). For instance, in Lb. acidophilus, fructooligosaccharides (FOSs) are transported by an adenosine triphosphate (ATP)-dependent binding cassette (ABC) transporter and hydrolyzed by intracellular $\beta$-fructofuranosidases $(\beta$ FFases). In $L b$. plantarum, FOS is internalized via a sucrose phosphoenol pyruvate-dependent, phosphotransferase system (PTS) transporter, and hydrolysis is catalyzed by a cytoplasmic $\beta$-FFase. Lactobacillus ruminus can translocate and hydrolyze
FOS and inulin via the major facilitator superfamily (MFS) transporter. On the other hand, galactooligosaccharide (GOS) is internalized via a galactosidepentose-hexuronide (GPH)-type lactose permease (LacS) transporters. FOS is catalysed by a cytoplasmic $\beta$-FFase, whereas GOS is hydrolysed by two cytoplasmic $\beta$-galactosidases (LacA and LacLM) (as cited in Huynh \& Liu, 2018). In addition, to utilize mannan oligosaccharide (MOS) as a sole carbon source, Lactobacillus species must contain polysaccharide utilization loci (PULs) namely MAN-PUL1, MAN-PUL2, and MAN-PUL3. Probiotic bacteria lacking MAN-PUL2 are unable to grow on MOS. This statement was also demonstrated in a study reported Huynh et al. (2018b). For this, Lb. plantarum 7-40 was able to utilize FOS and GOS as the sole of carbon sources, but MOS. In the present work, no fermenting occurred in the negative control (no sugar). In contrast, Lactobacillus was able to utilize the extracts from banana (Musa), sweet potato (Ipomoea), and glucose (positive control) as the sole carbon sources and produced acid end products. However, the sugar contents in the extracts from banana and sweet potato in this study are unknown. Therefore, the investigations of the degree of polymerization of the extracts in this study should be unraveled in further studies.

Till now, the sugar contents in banana Musa have been reported by several researchers. For example, Poland (1937) reported that the principal sugars of the ripe banana were definitely shown to be sucrose, maltose, fructose, and glucose, whereas maltose is present in very small amounts in commercial yellow banana (Musa sapientum).Additionally, according to Vietnam Ministry of Health (VMoH, 2007), total sugar in Siamese banana accounted for $12.2 \%$, whereas galactose and lactose were absent. However, high amounts of fructose $(4.85 \%)$ and glucose $(4.95 \%)$, followed by sucrose $(2.39 \%)$ and maltose $(0.1 \%)$. For sweet potato I. batatas, Lewthwaite et al. (1997) reported that sweet potato contained fructose, glucose, sucrose, and maltose. This study is in accordance with a previous study which concluded that the sum of glucose, fructose, and sucrose accounted for $85-96 \%$ and $17-54 \%$ of the total soluble sugars identified in the ethanol extracted fractions of sweet potato (Den et al., 1986). In addition, Lai et al. (2013) studied sugar composition of seven sweet potato cultivars. Results revealed that total sugar content in the fresh sweet potatoes varied from $8.41 \%$ to $4.5 \%$, in which maltose content was very low (0 0.39\%). Because 49.9 92.4\% of total sugars were sucrose, sucrose was the major sugar 
composition of fresh sweet potatoes. Interestingly, additions to the monosaccharides, oligosaccharides were also detected in the sweet potatoes. RosasRamírez et al. (2008) identified successfully five oligosaccharides containing in sweet potatoes using ${ }^{1} \mathrm{H}$ nuclear magnetic resonance (NMR)-based metabolomic analysis. According to research on the sugar compositions in banana and sweet potato above, it could explain why Lactobacillus sp. can utilize all extracts from banana and sweet potato as the sole of carbon sources for growth of Lactobacillus sp. However, the effects of the extracts in stimulating growth of Vibrio was not clear, especially in $V$. harveyi based on the $\mathrm{OD}_{600}$ at 24 hours and low prebiotic score (Figures 4B\&5) in this study.

Previous studies showed that prebiotic extracted from sweet potatoes could effectively support the growth of probiotic bacteria (Putra et al., 2010). Ringo et al. (2010) stated that prebiotic can selectively support the growth of species of bacteria in the digestive tract of shrimp. Therefore, the development of synbiotic by natural prebiotic extracts, including banana and sweet potatoes may be better in cost production in shrimp culture. To assess the specific stimulation of a prebiotic to a probiotic, measurement of the growth of probiotics that cultured in the medium containing prebiotic as the sole of carbon source likely lacks discipline, because interactions between a selective prebiotic and indigenous microbiota remain unknown (Kolida \& Gibson, 2011). Therefore, the effectiveness of a prebiotic depends on its ability to be selectively fermented by and to support the growth of specifically targeted probiotic. Regrettably, this issue has received less attention, although numerous commercial prebiotic and synbiotic products have intensively been used in aquaculture (Huynh et al., 2017). In this study, using $V$. haveryi and $V$. parahaemolyticus as references, the higher prebiotic score indicated that white sweet potato was a suitable prebiotic substrate for Lactobacillus sp. instead of using glucose as a carbon source for lactic fermentation.

The genus Lactobacillus is a diverse group of microorganisms. The genus comprises over 25 species and the first level of differentiation is based on endproduct composition. Lactobacillus is an important genus in the fermentation of various plant products, fermented fish products and marine environments. Lactobacillus isolates are capable of producing protease. L. plantarum strains are able to ferment oligosaccharides which may be used in synbiotic products. Among bacterial enzymes, protease is an enzyme that is able to hydrolyze peptide bonds of proteins. Sulthoniyah et al. (2015) revealed that protease enzyme from $L$. plantarum isolated from shrimp paste had optimum activity at $\mathrm{pH} 7.0$ with specific enzyme activity of $0.34 \mathrm{U} / \mathrm{mg}$ protein (Huynh \& Liu, 2018). It is also known that lactic acid bacteria possess a complex proteolytic system, although they are less proteolytic than other microorganisms. In this work, in presence of white sweet potato extract, Lactobacillus sp. exhibited higher production levels of protease enzymes that play important roles in protein digestibility as compared to those in the glucose control. The obtained results indicate that the extract from white sweet potato can be more suitable substrate for Lactobacillus sp. in this study. However, the effects of dietary combination of Lactobacillus sp. and white sweet potato in the whiteleg shrimp L. vannamei still need in further research.

\section{CONCLUSION}

Probiotic Lactobacillus sp. can utilize extracts from Arcera banana, Siamese bananas, orange-fleshed sweet potato, and white sweet potato. Extract from white sweet potato induced the highest growth of probiotic Lactobacillus sp., higher prebiotic activity; stimulated extracellular protease enzyme activities as compared to the positive control. It is, therefore, recommended that white sweet potato extract was more suitable substrate to combine with Lactobacillus sp.to be a relevant synbiotic for aquaculture uses.

\section{ACKNOWLEDGMENTS}

This study is funded in part by the Can Tho University Improvement Project VN14-P6, supported by a Japanese ODA loan. We appreciate Ms. Lam Anh Thu and Mr. Huynh Trung Hieu for their assistances with the experiments.

\section{REFERENCES}

Boonmee, R., \& Rengpipat, S. (2015). Effects of Musa (ABB group) prebiotic and Bacillus subtilis $\mathrm{S} 11$ probiotic on growth and disease resistance of cultivated Pacific white shrimp (Litopenaeus vannamei). Maejo International Journal of Science and Technology, 9(3), 370-381. https://doi.org/10.14456/mijst.2015.28

Cerezuela, R., Meseguer, J., \& Esteban, M. A. (2011). Current knowledge in synbiotic use for fish aquaculture:A review. Journal of Aquaculture Research and Development, S1, 008. https://doi.org/10.4172/21559546.S1-008

Van Den, T., Biermann, C.J., \& Marlett, J. A. (1986). Simple sugars, oligosaccharides, and starch concentrations in raw and cooked sweet potato. Journal of 
Agricultural and Food Chemistry, 34, 421-425. https://doi.org/10.1021/jf00069a010

Food and Agriculture Organization/World Health Organization [FAO/WHO] (2006). Probiotics in food. Health and nutritional properties and guidelines for evaluation. Report of a Joint FAO/WHO Expert Consultation on Evaluation of Health and Nutritional Properties of Probiotics in Food including Powder Milk with Live Lactic Acid Bacteria. http://www.fao.org/3/a-a0512e.pdf

Huynh, T. G., Shiu, Y. L., Nguyen, T. P., Truong, Q. P., Chen, J. C., \& Liu, C. H. (2017). Current applications, selection, and possible mechanisms of actions of synbiotics in improving the growth and health status in aquaculture: A review. Fish and Shellfish Immunology, 64, 367-382. https://doi.org/10.1016/j.fsi.2017.03.035

Huynh, T. G., \& Liu, C. H. (2018). Study on action mechanisms of synbiotic as growth-promoting factor in white shrimp Litopenaeus vannamei (Doctoral thesis on Aquaculture). National Pingtung University of Science and Technology.

Huynh, T. G., Cheng, A. C., Chi, C. C., Chiu, K. H, \& Liu, C. H. (2018a). A synbiotic improves the immunity of white shrimp, Litopenaeus vannamei: Metabolomic analysis reveal compelling evidence. Fish and Shellfish Immunology, 79, 284-293.

https://doi.org/10.1016/j.fsi.2018.05.031

Huynh, T. G., Shiu, Y. L., Nguyen, T. P., Hien, T. T. T., \& Liu, C. H. (2018b). Effects of synbiotic containing Lactobacillus plantarum 7-40 and galactooligosaccharide on the growth performance of white shrimp, Litopenaeus vannamei. Aquaculture Research, 49, 2416-2428. https://doi.org/10.1111/are.13701

Huynh, T. G., Nguyen, H. N. U., Vu, H. H., Pham, T. T. N., \& Vu, N. U. (2020). Characterization of potential probiotic Lactobacillus from whiteleg shrimp intestines for possible additives in pellet feeding. Can Tho University Journal of Science. Special Issues on Aquaculture, (1), 102-111. https://doi.org/10.22144/ctu.jsi.2020.012 (In Vietnamese with English abstract).

Kolida, S., \& Gibson, G. R. (2011). Synbiotics in health and disease. Annual Review of Food Science and Technology, 2, 373-393. https://doi.org/10.1146/annurev-food-022510-133739

Lai, Y. C., Huang, C. L., Chan, C. F., Lien, C. Y., \& Liao, W. C. (2013). Studies of sugar composition and starch morphology of baked sweet potatoes (Ipomoea batatas (L.) Lam). Journal of Food Science and Technology, 50, 1193-1199. https://doi.org/10.1007/s13197-011-0453-6

Lewthwaite, S. L., Sutton, K. H., \& Triggs, C. M. (1997). Free sugar composition of sweetpotato cultivars after storage. New Zealand Journal of Crop and Horticultural Science, 25(1), 33-41. https://doi.org/10.1080/01140671.1997.9513984
Li, J., Tan, B., \& Mai, K. (2009). Dietary probiotic Bacillus $\mathrm{OJ}$ and isomaltooligosaccharides influence the intestine microbial populations, immune responses and resistance to white spot syndrome virus in shrimp ( $\mathrm{Li}$ topenaeus vannamei). Aquaculture, 291, 35-40. https://doi.org/10.1016/j.aquaculture.2009.03.005

Liao, I. C. \& Chien, Y. H. (2011). The Pacific white Shrimp, Litopenaeus vannamei, in Asia: The world's most widely cultured alien crustacean. In B. S. Galil, P. F. Clark, \& J.T. Carlton (Eds.), In the wrong place - Alien marine crustaceans: Distribution, biology and impacts (p. 716). Invading Nature - Springer Series in Invasion Ecology 6. Springer: Dordrecht, the Netherlands. https://doi.org/10.1007/978-94-007-0591-3_17

Marlida, R., Suprayudi, M. A., Widanarni, \& Harris, E. (2014). Growth, digestive enzyme activity and health status of humpback grouper (Cromileptes altivelis) fed with synbiotic. Pakistan Journal of Nutrition, 13 (6), 319-326. https://doi.org/10.3923/pjn.2014.319.326

Mazzola, E., Perrone, G., \& Kamuriwo, D. S. (2015). Network embeddedness and new product development in the biopharmaceutical industry: the moderating role of open innovation flow. International Journal of Production Economic, 160, 106-119. https://doi.org/10.1016/j.ijpe.2014.10.002

Nurhayati, D., Widanarni, \& Yuhana, M. (2015). Dietary synbiotic influence on the growth performance and immune response to co-infection with infectious Myonecrosis virus and Vibrio harveyi in Litopenaeus vannamei. Journal of Fisheries and Aquatic Science, 10, 13-23. https://doi.org/10.3923/jfas.2015.13.23

Putra, A. N., \& Romdhonah, Y. (2019). Effects of dietary Bacillus NP5 and sweet potato extract on growth and digestive enzyme activity of dumbo catfsh Clarias sp. Jurnal Akuakultur Indonesia, 18(1), 80-88. https://doi.org/10.19027/jai.18.1.80-88

Putra, A. N., 2010. The study of probiotics, prebiotics and synbiotic to Improve growth performance on $\mathrm{Ti}$ lapia (Oreochromis niloticus) (master's thesis). Bogor Agricultural University, Indonesia.

Ringo, E., Olsen, R. E., Gifstad, T. O., Dalmo, R. A., Amlund, H., Hemre, G. I., \& Bakke, A. M. (2010). Prebiotics in aquaculture: a review. Aquaculture and Nutrition, 16, 117-136.https://doi.org/10.1111/j.13652095.2009.00731.x

Rosas-Ramírez, D., Escalante-Sánchez, E., \& PeredaMiranda, R. (2008). Five novels oligosaccharides from sweet potato (Ipomoea batatas (L.) Lam). Planta Medicine,74 (9), PH34. https://doi.org/10.1055/s-0028-1084879

Rossland, E., Borge, G. I. A., Langsrud, T., \& Sorhaug, T. (2003). Inhibition of Bacillus cereus by strains of Lactobacillus and Lactococcus in milk. International Journal of Food Microbiology, 89, 205-212. https://doi.org/10.1016/S0168-1605(03)00149-1

Sulthoniyah, S. T. M., Hardoko, \& Nursyam, H. (2015). Characterization of extracellular protease lactic acid 
bacteria from shrimp paste. Journal of Life Science and Biomedicine, 5(1), 1-5. http://jlsb.scienceline.com/attachments/article/33/J.

Vietnam Ministry of Health [VMoH] (2007). Vietnam food composition table. Medical Publishing House. In Vietnamese.
Widanarni \& Tanbiyaskur (2015). Application of probiotic, prebiotic and pynbiotic for the control of Streptococcosis in tilapia Oreochromis niloticus. Pakistan Journal of Biological Sciences, 18, 59-66. https://doi.org/10.3923/pjbs.2015.59.66. 